\title{
Perioperative administration of fibrinogen does not increase adverse cardiac and thromboembolic events after cardiac surgery
}

\author{
J. Fassl ${ }^{1}$, G. Lurati Buse ${ }^{1}$, M. Filipovic ${ }^{1,3}$, O. Reuthebuch ${ }^{2}$, K. Hampl ${ }^{4}$, M. D. Seeberger ${ }^{1}$ and D. Bolliger ${ }^{1 *}$ \\ ${ }^{1}$ Department of Anaesthesia, Surgical Intensive Care, Prehospital Emergency Medicine and Pain Therapy and ${ }^{2}$ Division of Cardiac Surgery, \\ University Hospital Basel, CH-4031 Basel, Switzerland \\ ${ }^{3}$ Institute of Anesthesiology, Cantonal Hospital, St Gallen, Switzerland \\ ${ }^{4}$ Institute of Anesthesiology, Spitalzentrum Biel, Biel-Bienne, Switzerland \\ *Corresponding author. E-mail: dabolliger@uhbs.ch
}

\section{Editor's key points}

- Fibrinogen concentrate is increasingly used to decrease bleeding after cardiac surgery.

- However, it has the potential to increase thrombotic events and safety data are lacking.

- This retrospective analysis examined the effect of fibrinogen administration to a target of $2 \mathrm{~g}$ litre ${ }^{-1}$ in cardiac surgical patients.

- There was no increase in mortality or adverse outcomes, but more data are required.
Background. Although infusion of fibrinogen concentrate is increasingly used in bleeding patients after cardiac surgery, safety data are scarce. We aimed to evaluate the effect of perioperative administration of fibrinogen concentrate on postoperative morbidity and mortality in patients undergoing cardiac surgery.

Methods. During a 2 yr study period, 991 patients underwent cardiac surgery at a single university centre and were eligible for propensity score (PS) matching. We matched 190 patients with perioperative infusion of fibrinogen concentrate (median dose $2 \mathrm{~g}$ ) with 190 controls without fibrinogen administration. After PS matching, crude outcome was analysed. Further, a multivariate logistic regression including additional risk factors for adverse outcome was performed. The primary endpoint was a composite of mortality and the occurrence of major cardiac and thromboembolic events within 1 yr. Secondary outcomes included mortality after 30 days and $1 \mathrm{yr}$ and the composite of mortality and adverse events after 30 days.

Results. The administration of fibrinogen concentrate was not associated with an increased risk for mortality and thromboembolic or cardiac events within 1 yr after cardiac surgery [unadjusted hazard ratio (HR) $0.91 ; 95 \%$ confidence interval (CI) $0.55-1.49 ; P=0.697]$. When using multivariate logistic regression model, the HR for adverse outcome in patients with administration of fibrinogen concentrate was 0.57 (95\% CI $0.25-1.17 ; P=0.101$ ). Similarly, the administration of fibrinogen concentrate did not adversely affect the secondary outcomes when applying unadjusted and multivariate regression analyses.

Conclusions. Our study strongly suggests that the administration of fibrinogen concentrates at low dose is not associated with thromboembolic complications or adverse outcomes after cardiac surgery.

Keywords: cardiac surgery; fibrinogen; thromboembolism; treatment outcome

Accepted for publication: 21 July 2014
Fibrinogen plays a critical role in the coagulation process, and it is increasingly recognized as one of the primary haemostatic targets in perioperative bleeding after cardiac surgery. ${ }^{1-4}$ Accordingly, several studies have found that higher pre- and postoperative fibrinogen concentrations were associated with lower bleeding volumes. ${ }^{25-8}$ Therefore, perioperative preservation of fibrinogen and the infusion of fibrinogen concentrate in the case of bleeding and haemodilution associated with hypofibrinogenaemia might be a key step in perioperative haemostasis. Preliminary data suggest that the infusion of fibrinogen concentrate reduced postoperative bleeding volumes and transfusion requirements. ${ }^{9-13}$ In contrast, a recent study including 84 patients undergoing cardiac surgery questioned the benefit in haemostasis resulting from the administration of fibrinogen concentrate or cryoprecipitate. ${ }^{7}$

In addition to the limited evidence regarding the appropriate indication, dosing, and efficacy of fibrinogen concentrate in the perioperative treatment of the bleeding patient undergoing cardiac surgery, ${ }^{14-16}$ fibrinogen is a procoagulatory drug, which could potentially cause thromboembolic complications 
and impair patient outcome. High fibrinogen levels are recognized as a risk factor for increased mortality in non-surgical patients. ${ }^{17} 18$ In surgical patients, a high preoperative fibrinogen level has been identified as risk factor for the development of vein graft stenosis after peripheral vascular surgery ${ }^{19}$ and has been associated with increased mortality after coronary surgery. ${ }^{20}$

At our institution, fibrinogen concentrate is regularly administered to bleeding patients after cardiac surgery. In this retrospective analysis of prospectively collected data, we aimed to evaluate the association between perioperative administration of fibrinogen concentrate to bleeding patients undergoing cardiac surgery and postoperative thromboembolic events and mortality after 30 days and $1 \mathrm{yr}$. We hypothesized that fibrinogen administration would increase neither postoperative thromboembolic and cardiac events nor short- and long-term mortality.

\section{Methods}

\section{Study design}

With the approval of the local ethics committee (amendment to EKBB 06/07, Ethikkommission beider Basel, Switzerland) and written informed consent from all patients, we performed a secondary retrospective analysis of prospectively collected data at the University Hospital Basel. The original study has recently been published. ${ }^{21}$ We included all patients undergoing cardiac surgery between January 2008 and December 2009 with the exception of patients undergoing surgery of the ascending aorta (with or without hypothermic circulatory arrest) or pericardiectomy. All patients fulfilling inclusion and exclusion criteria were eligible for propensity score (PS) matching (Fig. 1).

\section{Perioperative management}

Patients were orally premedicated with midazolam $(7.5 \mathrm{mg})$ or bromazepam (1.5-3 mg). Anaesthesia was induced by thiopental ( $\left.3-4 \mathrm{mg} \mathrm{kg}^{-1}\right)$ or etomidate $\left(0.2-0.3 \mathrm{mg} \mathrm{kg}^{-1}\right)$ and fentanyl $\left(2-6 \mu \mathrm{g} \mathrm{kg}^{-1}\right)$. Anaesthesia was maintained by isoflurane and midazolam/fentanyl infusion or by isoflurane and propofol infusion. Neuromuscular block was induced and maintained by atracurium. For procedures requiring cardiopulmonary bypass (CPB), systemic full-dose heparin (350 units $\mathrm{kg}^{-1}$ ) was administered as a bolus before cannulation with additional doses to maintain an activated clotting time (ACT) $>480 \mathrm{~s}$ ( plus ${ }^{\circledR}$ System, Metronic, Münchenbuchsee, Switzerland). Tranexamic acid (30 $\mathrm{mg} \mathrm{kg}^{-1}$ ) was given immediately after the initial dose of heparin. CPB priming volume amounted to $2000 \mathrm{ml}$. Myocardial protection was achieved by intermittent anterograde blood or crystalloid cardioplegia. For coronary artery bypass grafting without CPB, heparin was initially administered at a dose of 300 units $\mathrm{kg}^{-1}$ with additional doses to maintain ACT >350 s. No tranexamic acid was given during off-pump procedures. Body temperature was maintained at $>32^{\circ} \mathrm{C}$ during $\mathrm{CPB}$ and at $>36^{\circ} \mathrm{C}$ during off-pump surgery. CPB weaning was managed with catecholamines at the discretion of the attending anaesthesiologist. Heparin reversal was achieved by protamine aiming for ACT values within $\pm 10 \%$ of the value before surgery.

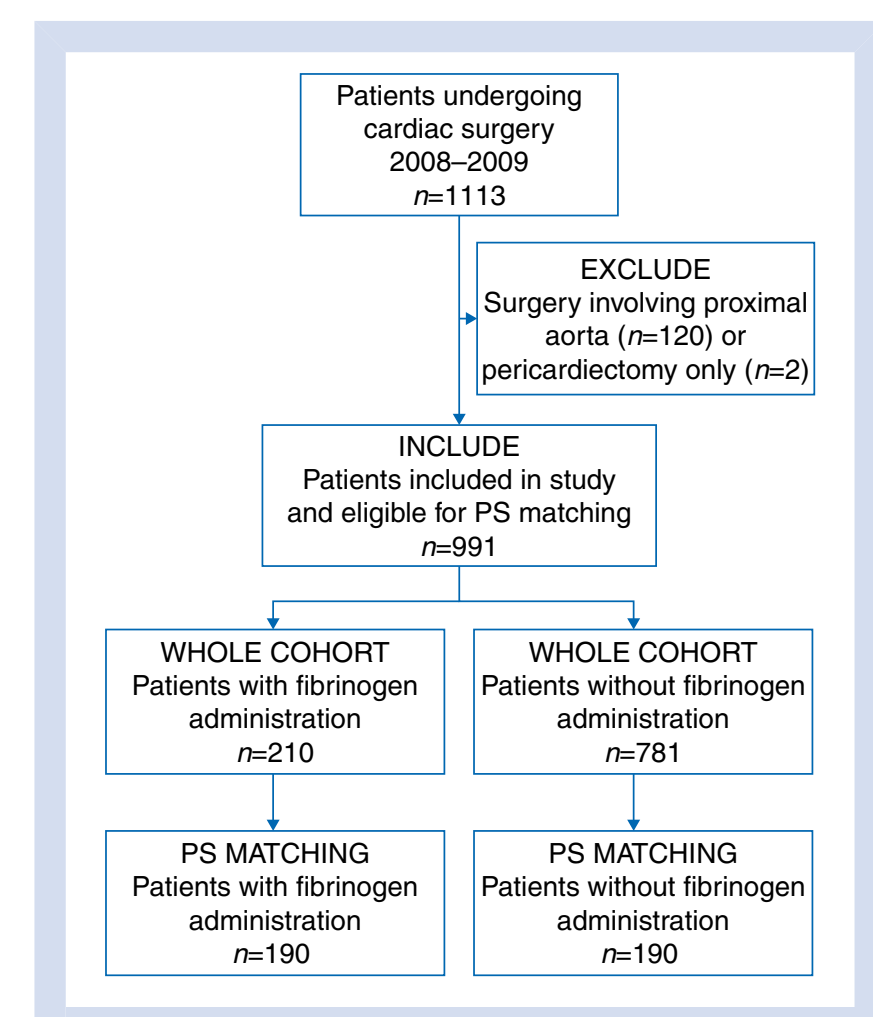

Fig 1 Flow chart of inclusion and exclusion. PS, propensity score.

The following triggers for infusion of fibrinogen concentrate and transfusion of allogeneic blood products were used during the perioperative period: fibrinogen concentrate was administered to bleeding patients according to our ROTEM ${ }^{\circledR}$ algorithm (FIBTEM $^{\circledR}$ maximal clot firmness $<8 \mathrm{~mm}$ ), ${ }^{22}$ or fibrinogen plasma concentration $<2 \mathrm{~g}$ litre ${ }^{-1} \cdot{ }^{23}$ A minimum haemoglobin concentration of $>65 \mathrm{~g}^{\text {litre }}{ }^{-1}$ was required during CPB. After CPB and in the intensive care unit (ICU), patients with a haemoglobin concentration of $<70 \mathrm{~g}$ litre ${ }^{-1}$ were given red blood cell (RBC) transfusion; patients with a haemoglobin concentration of $70-100 \mathrm{~g}$ litre ${ }^{-1}$ were treated according to the discretion of the physician in charge when the following transfusion triggers occurred: persistent bleeding, haemodynamic instability, and signs of myocardial ischaemia. Patients with a haemoglobin concentration of $>100 \mathrm{~g}$ litre ${ }^{-1}$ were not given RBC transfusion. Fresh-frozen plasma (FFP) and platelets were given to clinically bleeding patients according to our ROTEM ${ }^{\circledR}$ algorithm, ${ }^{22}$ in the case of low platelet count $\left(<50000 \times 10^{9}\right.$ litre $\left.^{-1}\right)$ or prolonged prothrombin time. However, in a small minority of patients with clinically massive bleeding or preoperative use of platelet aggregation inhibitors, procoagulatory products were transfused based on the judgement of the attending physician only.

\section{Data collection and endpoint ascertainment}

Trained research personnel prospectively collected detailed data on patient characteristic, surgical techniques, blood transfusion, pre-and postoperative laboratory testing, administration of coagulation factor concentrates, and in-hospital course and clinically important adverse events. Data on adverse events 
during hospitalization defined as thoracic re-exploration, acute (new-onset) renal impairment, severe brain injury, stroke, pulmonary, mesenteric or peripheral thromboembolism, myocardial infarction, and coronary re-intervention were collected during hospitalization and follow-up.

The primary endpoint was defined as the composite of allcause mortality, the occurrence of non-fatal major adverse cardiac events defined as myocardial infarction, need for subsequent surgical or percutaneous coronary intervention, congestive heart failure requiring hospitalization within $1 \mathrm{yr}$ after surgery, and any thromboembolic event including stroke, mesenteric ischaemia, peripheral arterial thromboembolism, pulmonary embolism, and deep vein thrombosis within $1 \mathrm{yr}$. Secondary endpoints were the composite of death and nonfatal major adverse cardiac or thromboembolic event within 30 days, and all-cause mortality within 30 days and $1 \mathrm{yr}$.

Data on events were prospectively collected from clinical charts during hospitalization. Follow-up occurred by a mailed questionnaire $1 \mathrm{yr}$ after surgery. Patients or next of kin were asked to complete a simple questionnaire on the occurrence and date of any hospitalization within $1 \mathrm{yr}$ after surgery, the patient's vital status, or both, respectively. If the questionnaire was not returned, we contacted the patient by telephone for a semi-structured interview. The interviews were conducted by a trained study nurse, blinded to all patient data. If the questionnaire or the interview indicated that the patient was hospitalized for any reason, we contacted the hospital or the patient's general practitioner to obtain the discharge letters. If direct contact with a patient could not be established, we asked the patient's general practitioner to provide the required health status information. Based on this information, the occurrence of the endpoints during hospitalization and follow-up was determined by two independent assessors blinded to all patient data according to the pre-specified definitions. In the case of disagreement, consensus was reached by discussion.

\section{Statistics analysis}

Patients with and without administration of fibrinogen concentrate were compared with regard to continuous and categorical baseline variables in the whole cohort and in PS-matched cohort. The PS was calculated as the probability of administration of fibrinogen concentrate for each patient in the whole cohort. The binary endpoint 'fibrinogen administration' was predicted using a logistic regression model (propensity model). The following 20 variables were included: age, gender, preoperative fibrinogen concentration, haemoglobin, platelet count, international normalized ratio, C-reactive protein, preoperative left ventricular ejection fraction, preoperative therapy with aspirin or clopidogrel, preoperative treatment with vitamin $\mathrm{K}$ antagonists, history of arterial hypertension, diabetes, hypercholesterolaemia, cerebral insult, peripheral artery occlusive disease, atrial fibrillation, numeric EuroSCORE I, ${ }^{24}$ surgical procedure, and CPB time. Twenty (10\%) and 76 patients (10\%) with and without fibrinogen concentrate, respectively, were excluded from PS matching because of incomplete data in any of the matching variables. The 190 cases with administration of fibrinogen concentrate were matched by PS with 190 controls without administration of fibrinogen concentrate, yielding a matched data set including 380 patients. The procedure included nearest neighbour matching on the linear PS using a maximum calliper width of 0.2 SD of the linear PS. ${ }^{25}$ The actual calliper was 0.21 , resulting in a good overlap of PS between cases and the matched controls.

After PS matching, crude outcome was analysed in the PS-matched cohort. In addition, univariate and multivariate logistic regression models in the PS-matched cohort and in the whole cohort were performed including different variables with potential influence on outcome. In the multivariate models, the following five independent variables were included as they were associated with adverse outcome in the univariate analysis: administration of fibrinogen concentrate (binary), major bleeding (binary), peak postoperative troponin level (per $0.1 \mathrm{ng} \mathrm{ml}^{-1}$ increase), ${ }^{21}{ }^{26}$ number of administered allogeneic blood products (continuous), and number of postoperative complications unrelated to bleeding ('other complications') (continuous). Major bleeding was defined as postoperative bleeding volumes $>1000 \mathrm{ml}$ during $24 \mathrm{~h}$ or the need for surgical re-exploration because of bleeding. ${ }^{22}$ Allogeneic blood products included RBC concentrates, platelet concentrates, and FFP. Other postoperative complications included the need for renal replacement therapy, mechanical circulatory support, re-intubation, and sepsis.

Continuous data were presented as mean (SD) or as median [inter-quartile range (IQR)] where appropriate. Categorical data were presented as numbers and percentages. Cases and controls were compared by Student's t-test, Mann-Whitney $U$-test, or $\chi^{2}$ test where appropriate. Events were compared by the Kaplan-Meier curves and the Cox proportional-hazards survival model. Perioperative fibrinogen concentrations were compared by a general linear model followed by Bonferroni's post hoc test.

Assuming an incidence rate of $\sim 14 \%,{ }^{26}$ resulting in $\sim 50$ events in the PS-matched population, our sample size would allow a robust logistic regression model including up to five variables. ${ }^{27} \mathrm{~A}$ P-value of $<0.05$ was considered significant. Statistical analyses were performed using IBM SPSS Statistics 21 (IBM Corp., Armonk, NY, USA).

\section{Results}

Patients' characteristics and details on cardiac surgery of the whole cohort $(n=991)$ and the matched cohort $(n=380)$ are provided in Tables 1 and 2, respectively. Thirty day and $1 \mathrm{yr}$ follow-up were complete in $99.5 \%$ and $99.2 \%$ in the whole cohort, respectively, and in $100 \%$ in the matched cohort. Table 3 compares postoperative bleeding volumes, use of allogeneic blood products, and important parameters after cardiac surgery in the PS-matched cohort.

\section{Perioperative administration of fibrinogen concentrates}

In the fibrinogen group, the median (range) amount of fibrinogen administration was $0(0-4)$ and $2(0-21) \mathrm{g}$ in the operation 
Table 1 Patient characteristics and details on cardiac surgery in the whole cohort. Data are mean (SD), median (IQR), or number of patients (proportion). $P$-values were calculated by Student's $t$-test, $\chi^{2}$ test or Mann-Whitney $U$-test, where appropriate. CABG, coronary artery bypass grafting; CRP, C-reactive protein; CPB, cardiopulmonary bypass; INR, international normalized ratio; LV-EF, left ventricular ejection fraction

\begin{tabular}{|c|c|c|c|c|}
\hline & All patients $(n=991)$ & Fibrinogen administration $(n=210)$ & No fibrinogen $(n=781)$ & $P$-value \\
\hline Age (yr) & $68(61-76)$ & $68(60-76)$ & $68(61-75)$ & 0.684 \\
\hline Male gender & $727(73)$ & $166(79)$ & $561(72)$ & 0.038 \\
\hline Weight (kg) & $80(16)$ & $78(17)$ & $80(15)$ & 0.209 \\
\hline Height (cm) & $171(9)$ & $171(9)$ & 170 (9) & 0.265 \\
\hline Haemoglobin (g litre ${ }^{-1}$ ) & $134(16)$ & $136(17)$ & $134(16)$ & 0.125 \\
\hline Haematocrit (litre litre ${ }^{-1}$ ) & $39(5)$ & $39(5)$ & $38(4)$ & 0.126 \\
\hline Platelet count $\left(\times 10^{9}\right.$ litre $^{-1}$ ) & $270(88)$ & $247(71)$ & $276(91)$ & $<0.001$ \\
\hline INR & $1.1(0.3)$ & $1.1(0.3)$ & $1.1(0.3)$ & 0.976 \\
\hline CRP (mg litre ${ }^{-1}$ ) & $2.5(1.0-6.4)$ & $1.6(0.6-4.0)$ & $2.7(1.2-6.8)$ & 0.007 \\
\hline Fibrinogen ( litre $^{-1}$ ) & $3.4(0.8)$ & $3.1(0.7)$ & $3.5(0.8)$ & $<0.001$ \\
\hline Aspirin therapy & $740(75)$ & $168(80)$ & $572(73)$ & 0.347 \\
\hline Clopidogrel therapy & $205(21)$ & $63(30)$ & $142(18)$ & 0.001 \\
\hline Oral anticoagulants & $131(13)$ & $32(15)$ & $99(13)$ & 0.319 \\
\hline Arterial hypertension & $722(73)$ & $136(65)$ & $586(75)$ & 0.002 \\
\hline Diabetes, treated & $242(25)$ & $43(21)$ & $199(26)$ & 0.129 \\
\hline History of stroke & $81(8)$ & $20(10)$ & $61(8)$ & 0.413 \\
\hline Atherosclerosis & $121(12)$ & $23(11)$ & $98(13)$ & 0.523 \\
\hline Atrial fibrillation & $125(13)$ & $29(14)$ & $96(12)$ & 0.561 \\
\hline LV-EF (\%) & $56(13)$ & $54(13)$ & $56(13)$ & 0.051 \\
\hline EuroSCORE I $\mathrm{I}^{24}$ & $5(2-7)$ & $5(3-7)$ & $5(2-7)$ & 0.971 \\
\hline Cardiac surgery & & & & 0.006 \\
\hline Single CABG & $535(54)$ & $100(48)$ & $435(56)$ & \\
\hline Off-pump & $26(3)$ & $4(2)$ & $22(3)$ & \\
\hline Single non-CABG & $224(23)$ & $44(21)$ & $180(23)$ & \\
\hline Two procedures & $215(22)$ & $60(29)$ & $155(20)$ & \\
\hline Three procedures & $16(1)$ & $6(3)$ & $10(1)$ & \\
\hline Emergent surgery & $30(3)$ & $12(5)$ & $18(2)$ & 0.007 \\
\hline CPB time (min) & $98(77-126)$ & $110(86-143)$ & $94(76-123)$ & $<0.001$ \\
\hline Cross-clamp time (min) & $62(47-84)$ & $71(51-92)$ & $60(46-80)$ & $<0.001$ \\
\hline
\end{tabular}

theatre and in the ICU, respectively. The median (range) total amount of administered fibrinogen concentrate was 2 (1-25) g.

Perioperative fibrinogen concentrations in cases with administration of fibrinogen concentrates and matched controls are shown in Figure 2. The course of perioperative fibrinogen concentrations were similar in both groups $(P=0.815)$. All postoperative fibrinogen concentrations were significantly different from baseline values (all $P<0.001$ ). The corresponding fibrinogen plasma concentrations in the whole cohort were comparable (data not shown).

\section{Mortality and combined endpoint incidences}

In the PS-matched cohort, all-cause mortality within 30 days and $1 \mathrm{yr}$ was $7.1 \%$ and $8.4 \%$, respectively (Fig. $3 \mathrm{~A}$ ). The combined endpoint of mortality and adverse cardiac or thromboembolic events after 30 days and $1 \mathrm{yr}$ was reached in $7.4 \%$ and $16.3 \%$, respectively (Fig. $3 \mathrm{~B}$ ). Unadjusted hazard ratios (HR) for the primary and secondary adverse outcomes in patients with fibrinogen administration were between 0.79 [95\% confidence interval (CI) $0.39-1.58$ ] and 1.46 (95\% CI
0.55-3.82) ( $P$-values between 0.678 and 0.446$)$ compared with matched controls (Fig. $3 \mathrm{~A}$ and $\mathrm{B}$ ).

In the whole cohort, all-cause mortality within 30 days and $1 \mathrm{yr}$ was $5.1 \%$ and $7.1 \%$, respectively. The combined endpoint of adverse cardiac or thromboembolic events after 30 days and $1 \mathrm{yr}$ was reached in $7.0 \%$ and $14.3 \%$, respectively. In the whole cohort, unadjusted HRs for the primary and secondary adverse outcomes in patients with fibrinogen administration were between 1.19 (95\% CI $0.81-1.75)$ and 1.56 (95\% CI $0.80-3.04$ ) (P-values between 0.495 and 0.194 ) compared with matched controls.

\section{Univariate and multivariate logistic regression models}

In the univariate regression model, major bleeding, the peak troponin levels, transfusion of blood products, and the occurrence of postoperative complications unrelated to bleeding were associated with the primary endpoint, whereas the administration of fibrinogen concentrate was not (Table 4). Univariate HRs in the whole cohort were comparable (data not shown). After multivariate adjustment, the administration of 
Table 2 Patient characteristics and details on cardiac surgery in the cases and controls after PS matching. Data are mean (SD), median (IQR), or number of patients (proportion). $P$-values were calculated by Student's t-test, $\chi^{2}$ test, or Mann-Whitney U-test, where appropriate. CABG, coronary artery bypass grafting; CRP, C-reactive protein; CPB, cardiopulmonary bypass; INR, international normalized ratio; LV-EF, left ventricular ejection fraction

\begin{tabular}{|c|c|c|c|}
\hline & Fibrinogen $(n=190)$ & No fibrinogen $(n=190)$ & $P$-value \\
\hline Age (yr) & $68(60-76)$ & $68(61-76)$ & 0.712 \\
\hline Male gender & $150(79)$ & $154(81)$ & 0.701 \\
\hline Haemoglobin ( litre $^{-1}$ ) & $135(17)$ & $136(16)$ & 0.485 \\
\hline Platelet count $\left(\times 10^{9}\right.$ litre $^{-1}$ ) & $248(72)$ & $252(79)$ & 0.575 \\
\hline INR & $1.1(0.3)$ & $1.1(0.3)$ & 0.624 \\
\hline Fibrinogen & $3.1(0.7)$ & $3.1(0.6)$ & 0.610 \\
\hline CRP (mg litre ${ }^{-1}$ ) & $1.6(0.7-3.8)$ & $1.7(0.8-4.4)$ & 0.761 \\
\hline Aspirin therapy & $147(77)$ & $147(77)$ & 1.000 \\
\hline Clopidogrel therapy & $52(27)$ & $49(26)$ & 0.816 \\
\hline Oral anticoagulants & $28(14)$ & $30(16)$ & 0.887 \\
\hline Arterial hypertension & $123(65)$ & $125(66)$ & 0.914 \\
\hline Hypercholesterolaemia & $104(55)$ & $104(55)$ & 1.000 \\
\hline Diabetes, treated & $40(21)$ & $47(25)$ & 0.464 \\
\hline Peripheral atherosclerosis & $21(11)$ & $27(14)$ & 0.440 \\
\hline History of stroke & $17(9)$ & $19(10)$ & 0.861 \\
\hline Atrial fibrillation & $26(14)$ & $26(14)$ & 1.000 \\
\hline LV-EF (\%) & $55(13)$ & $54(13)$ & 0.722 \\
\hline EuroSCORE I ${ }^{24}$ & $5(3-7)$ & $5(3-7)$ & 0.457 \\
\hline Cardiac surgery & & & 0.265 \\
\hline Single CABG & $87(45)$ & $93(49)$ & \\
\hline Off-pump & $3(2)$ & $3(2)$ & \\
\hline Single non-CABG & $42(22)$ & $45(24)$ & \\
\hline Two procedures & $55(29)$ & $50(26)$ & \\
\hline Three procedures & $6(3)$ & $2(1)$ & \\
\hline CPB time (min) & $110(86-144)$ & $104(86-144)$ & 0.638 \\
\hline
\end{tabular}

Table 3 Postoperative complications and transfusion of blood products. Data are median (IQR) or numbers of patients (proportion). P-values were calculated by the Mann-Whitney U-test or $\chi^{2}$ test, where appropriate. FFP, fresh-frozen plasma; PCC, prothrombin complex concentrate; RBC, red blood cell

\begin{tabular}{lccr}
\hline & Fibrinogen $(\boldsymbol{n}=\mathbf{1 9 0})$ & No fibrinogen $(\boldsymbol{n}=\mathbf{1 9 0 )}$ & $\boldsymbol{P}$-value \\
\hline Highest creatinine level $\left(\mu \mathrm{mol}\right.$ litre $\left.{ }^{-1}\right)$ & $101(80-135)$ & $96(82-123)$ & 0.525 \\
Renal replacement therapy & $8(4)$ & $7(4)$ & 1.000 \\
Bleeding volume, postop (ml) & $1100(650-1750)$ & $750(500-1100)$ & $<0.001$ \\
Surgical re-exploration because of bleeding & $39(21)$ & $13(7)$ & $<0.001$ \\
Major bleeding & $63(30)$ & $18(10)$ & $<0.001$ \\
Median fibrinogen dose & $2(2-4)$ & $0(0-0)$ & $<0.001$ \\
Patients with PCC administration & $39(21)$ & $0(2)$ & $<0.2400)$ \\
Median PCC dosage & $0(0-2400)$ & $1(0-2)$ & 0.591 \\
RBC concentrate (units) & $3(1-5)$ & $111(58)$ & $<0.001$ \\
Patients with RBC transfusion & $163(86)$ & $0(0-0)$ & $<0.001$ \\
FFP concentrate (units) & $0(0-4)$ & $25(13)$ & $<0.001$ \\
Patients with FFP transfusion & $78(40)$ & $0(0-0)$ & $<0.001$ \\
Platelet concentrate (units) & $0(0-0)$ & $8(4)$ & $<0.001$ \\
Patients with platelet transfusion & $41(22)$ & & $<0.001$ \\
\hline
\end{tabular}

fibrinogen was not associated with mortality or the combined endpoint of mortality and adverse cardiac or thromboembolic events after 30 days and $1 \mathrm{yr}$ (Table 5). HRs for adverse events in patients with administration of fibrinogen concentrate were between 0.48 (95\% CI 0.37-1.13) and 0.75 (95\% CI 0.25-2.37) $(P$-values between 0.651 and 0.090$)$ for the various primary 
and secondary endpoints. Whereas postoperative complications were consistently associated with adverse outcomes and mortality, the transfusion of allogeneic blood product was not. Major bleeding was associated with adverse outcome in the combined endpoints after 30 days and $1 \mathrm{yr}$.

\section{Discussion}

The results of the present study suggest that perioperative administration of fibrinogen concentrate to bleeding patients

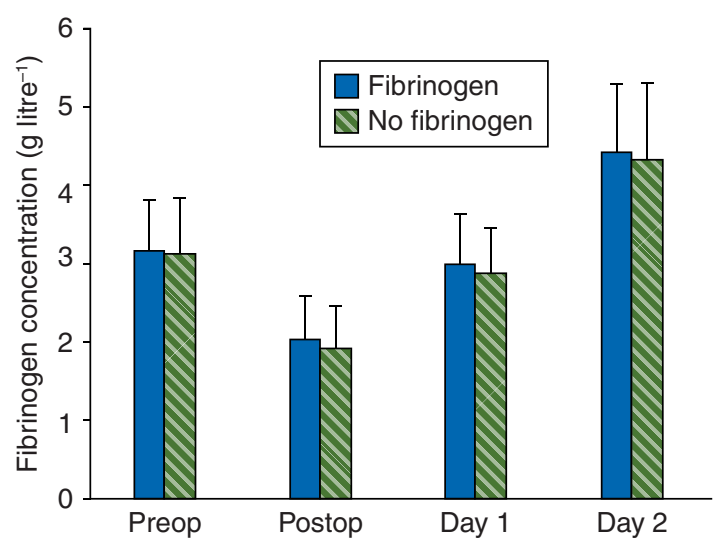

Fig 2 Perioperative fibrinogen concentrations in cases with fibrinogen administration and PS-matched controls without fibrinogen administration before surgery (Preop), directly after surgery (Postop), and in the morning of the first (Day 1) and second day (Day 2) after surgery. No significant difference in perioperative fibrinogen concentrations between the two groups were found $(P=0.815)$. undergoing cardiac surgery is not associated with increased incidence of major adverse cardiac and thromboembolic events and mortality after 30 days and $1 \mathrm{yr}$. These findings were consistently demonstrated both in a PS-matched casecontrol analysis and in a multivariate logistic regression model.

Fibrinogen concentrates are licensed for the treatment of acquired hypofibrinogenaemia only in some European countries. ${ }^{3}$ However, its administration has been advocated by the recent European guidelines on the management of severe perioperative bleeding as a $1 \mathrm{C}$ recommendation. ${ }^{28}$ While the evidence for this recommendation is still debated, ${ }^{14}{ }^{29}$ data on the risk of potential thrombotic events are limited. Based on

Table 4 Univariate model for the primary endpoint in the PS-matched population. CI, confidence interval; HR, hazard ratio; ICU, intensive care unit; PCC, prothrombin complex concentrate

\begin{tabular}{|c|c|c|c|}
\hline Comb & HR & $95 \% \mathrm{CI}$ & $P$-value \\
\hline $\begin{array}{l}\text { Fibrinogen administration, yes } \\
\text { vs no }\end{array}$ & 6 & 486 & 0.697 \\
\hline Administration of PCC & 367 & 0.67 & 0.385 \\
\hline Highe & 58 & $4.816-27.933$ & .001 \\
\hline Major & 15 & $1.894-$ & 0.001 \\
\hline Posto & 11.558 & $4.552-29.346$ & $<0.001$ \\
\hline $\begin{array}{l}\text { Renal replace } \\
\text { vs no }\end{array}$ & 5.991 & $2.946-12.182$ & $<0.001$ \\
\hline $\begin{array}{l}\text { Mechanical circulatory support, } \\
\text { yes vs no }\end{array}$ & 897 & $3.136-11.087$ & $<0.001$ \\
\hline Re-intubation on ICU, yes vs no & 8.389 & $3.783-18.606$ & $<0.001$ \\
\hline $\begin{array}{l}\text { Number of allogeneic blood } \\
\text { products }\end{array}$ & 1.041 & $1.021-1.061$ & $<0.001$ \\
\hline
\end{tabular}

B

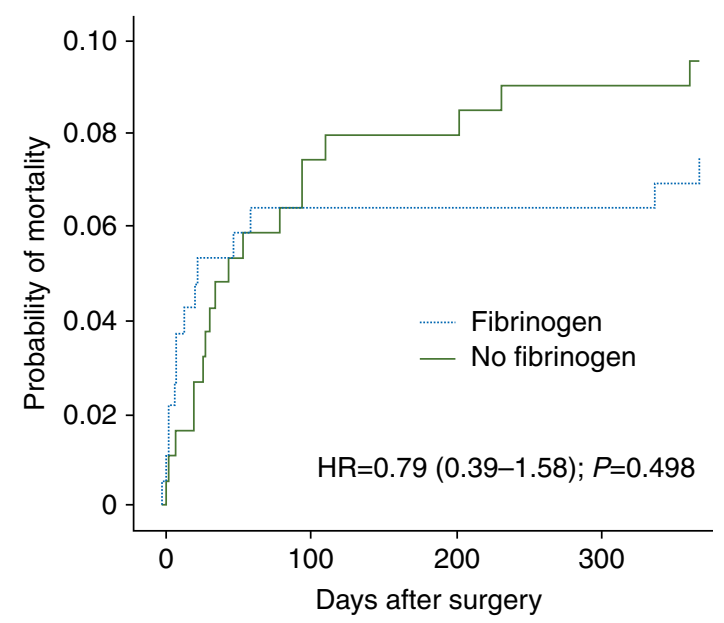

Patients at risk

$\begin{array}{lllll}\text { Fibrinogen } & 190 & 169 & 163 & 161 \\ \text { No fibrinogen } & 190 & 163 & 158 & 155\end{array}$

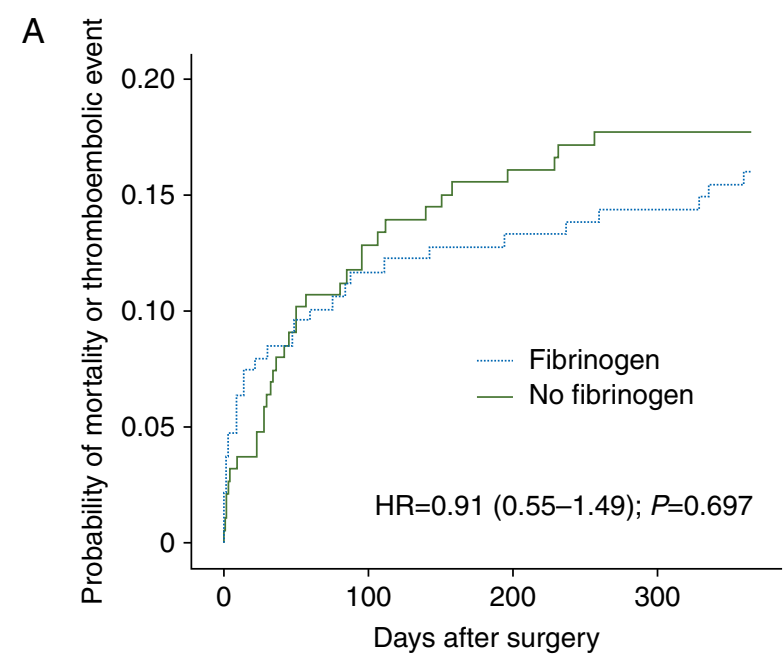

No fibrinogen 190
Patients at risk

\section{Fibrinogen 190}

No fibrinogen 190

$\begin{array}{lll}176 & 176 & 176 \\ 176 & 175 & 173\end{array}$

Fig 3 Kaplan-Meier survival curves for combined endpoint (A) and mortality (B). Probability of mortality, thromboembolic event, or both in patients with and without perioperative fibrinogen administration. Data are HR and their $95 \%$ confidence interval. $P$-values were derived from log-rank test. 
Table 5 Multivariate models for primary and secondary endpoints. $\mathrm{CI}$, confidence interval; HR, hazard ratio

\begin{tabular}{|c|c|c|c|}
\hline & HR & $95 \% \mathrm{CI}$ & $P$-value \\
\hline \multicolumn{4}{|l|}{ Combined endpoint $1 \mathrm{yr}$} \\
\hline $\begin{array}{l}\text { Fibrinogen administration, } \\
\text { yes vs no }\end{array}$ & 0.572 & $0.251-1.171$ & 0.101 \\
\hline Major bleeding & 3.292 & $1.717-6.314$ & $<0.001$ \\
\hline $\begin{array}{l}\text { Number of allogeneic blood } \\
\text { products }\end{array}$ & 0.996 & $0.964-1.030$ & 0.824 \\
\hline $\begin{array}{l}\text { Number of other } \\
\text { postoperative complications }\end{array}$ & 2.012 & $1.399-2.894$ & $<0.001$ \\
\hline $\begin{array}{l}\text { Highest troponin } \\
\text { concentration }\end{array}$ & 5.998 & $1.794-20.057$ & 0.004 \\
\hline \multicolumn{4}{|l|}{ Mortality $1 \mathrm{yr}$} \\
\hline $\begin{array}{l}\text { Fibrinogen administration, } \\
\text { yes vs no }\end{array}$ & 0.478 & $0.367-1.126$ & 0.090 \\
\hline Major bleeding & 1.793 & $0.678-4.737$ & 0.239 \\
\hline $\begin{array}{l}\text { Number of allogeneic blood } \\
\text { products }\end{array}$ & 1.020 & $0.981-1.060$ & 0.328 \\
\hline $\begin{array}{l}\text { Number of other } \\
\text { postoperative complications }\end{array}$ & 3.907 & $2.519-6.058$ & $<0.001$ \\
\hline $\begin{array}{l}\text { Highest troponin } \\
\text { concentration }\end{array}$ & 1.143 & $0.198-6.590$ & 0.881 \\
\hline \multicolumn{4}{|l|}{ Combined endpoint 30 days } \\
\hline $\begin{array}{l}\text { Fibrinogen administration, } \\
\text { yes vs no }\end{array}$ & 0.532 & $0.220-1.289$ & 0.162 \\
\hline Major bleeding & 3.955 & $1.581-9.895$ & 0.003 \\
\hline $\begin{array}{l}\text { Number of allogeneic blood } \\
\text { products }\end{array}$ & 1.016 & $0.982-1.051$ & 0.369 \\
\hline $\begin{array}{l}\text { Number of other } \\
\text { postoperative complications }\end{array}$ & 1.754 & $1.159-2.654$ & 0.008 \\
\hline $\begin{array}{l}\text { Highest troponin } \\
\text { concentration }\end{array}$ & 6.783 & $2.149-21.406$ & 0.001 \\
\hline \multicolumn{4}{|l|}{ Mortality 30 days } \\
\hline $\begin{array}{l}\text { Fibrinogen administration, } \\
\text { yes vs no }\end{array}$ & 0.753 & $0.243-2.339$ & 0.624 \\
\hline Major bleeding & 1.658 & $0.466-5.925$ & 0.435 \\
\hline $\begin{array}{l}\text { Number of allogeneic blood } \\
\text { products }\end{array}$ & 1.029 & $0.989-1.071$ & 0.155 \\
\hline $\begin{array}{l}\text { Number of other } \\
\text { postoperative complications }\end{array}$ & 2.612 & $1.512-4.512$ & 0.001 \\
\hline $\begin{array}{l}\text { Highest troponin } \\
\text { concentration }\end{array}$ & 2.549 & $0.364-17.857$ & 0.346 \\
\hline
\end{tabular}

the post-market surveillance data, thromboembolic complications directly associated with the administration of fibrinogen concentrate seem to be uncommon. ${ }^{30}$ However, the incidences of thromboembolic complications based on the post-market vigilance underestimate the actual event rates; ${ }^{23}$ and higher incidences might occur in cardiac surgery where postoperative cardiac and thromboembolic events are common. ${ }^{26} \mathrm{~A}$ recent Cochrane review identified only three randomized controlled trials including 124 patients-of them 61 patients with fibrinogen therapy-addressing the risk of thrombotic events after the administration of fibrinogen concentrate. ${ }^{16}$ Our study add further evidence suggesting that perioperative administration of fibrinogen concentrate in patients undergoing cardiac surgery might not increase the risk of postoperative adverse outcomes including thrombotic events.

Fibrinogen is the coagulation factor present in the highest concentration in blood and has a key role in haemostasis. ${ }^{3}$ However, several previous studies observed an association of elevated fibrinogen concentrations and the increased risk for both cardiovascular disease, ${ }^{31-33}$ venous thrombosis, ${ }^{34}$ and vein graft stenosis. ${ }^{19}$ The potential causative association has been questioned for several reasons. ${ }^{35-37}$ First, genetic polymorphisms seem to be more important in the individual risk assessment. ${ }^{35}$ Secondly, fibrinogen is up-regulated with the acute phase reaction and appears to be an important marker of severe atherosclerosis and inflammatory state rather than a causative factor. ${ }^{38}$ Thirdly, fibrin clot structure might be more relevant for thromboembolic risk assessment than the fibrinogen concentration itself, ${ }^{35}$ and increased fibre density and resistance to fibrinolysis might essentially contribute to the increased risk for cardiovascular diseases and thrombosis. ${ }^{39} 40$

Further, bleeding after cardiac surgery leads to loss and consumption of all procoagulants. Whereas thrombin generation seems to be relatively well preserved during blood loss and consecutive haemodilution, ${ }^{14142}$ fibrinogen has been shown to be the first clotting factor to reach critically low concentrations. ${ }^{43}$ Accordingly, both preoperative and postoperative fibrinogen concentrations have been shown to be predictive of postoperative bleeding in patients undergoing coronary artery bypass graft (CABG) surgery. ${ }^{5-7}$ Two recent clinical studies suggested that a postoperative fibrinogen concentration of $<2 \mathrm{~g}$ litre $^{-1}$ was associated with increased postoperative bleeding volumes. ${ }^{2}{ }^{5}$ Fibrinogen substitution aiming for such levels might, therefore, be a key step in managing postoperative bleeding after cardiac surgery. ${ }^{11}$ Our data provide no evidence that fibrinogen substitution in acquired hypofibrinogenaemia aiming to achieve plasma concentrations in the lower normal range (i.e. $2 \mathrm{~g}$ litre ${ }^{-1}$ ) is associated with increased thromboembolic events, mortality, or both.

The lack of an increased thromboembolic risk after fibrinogen administration in our study is in agreement with several clinical and experimental studies. ${ }^{9} 30445$ This might, at least in part, be explained by several factors. First, the risk of overdosing fibrinogen may be counteracted both by increased consumption of fibrinogen during haemorrhage and by haemodilution. ${ }^{42}$ Secondly, fibrin clot structure, an important factor for thrombotic potential, ${ }^{35}$ is relevantly dependent on thrombin generation. ${ }^{1}$ In haemodilution, clot structure is presumed to be loose and having larger pores, which lead to reduced clot firmness, and prone to fibrinolysis. ${ }^{41}$ Thirdly, fibrin clot structure is affected by both aspirin and statins which have been reported to reduce fibrin fibre density and increase fibrinolysis rates. ${ }^{35}$ Fourthly, besides its important role in haemostasis and clot formation, fibrinogen exerts an anticoagulant function by binding thrombin with high affinity, by modulating thrombin activity, and by inhibiting thrombinmediated factor $\mathrm{V}$ activation. ${ }^{146}$ Fibrinogen has, therefore, been previously described as antithrombin $\mathrm{I}^{47}$ Finally, fibrinogen concentrations showed rapid recovery after cardiac surgery, which is well explained by high production rate in 
the liver of $\sim 2-5 \mathrm{~g} \mathrm{day}^{-1}$. In agreement with a former study, ${ }^{48}$ this postoperative recovery of fibrinogen concentrations was comparable in the groups with and without fibrinogen substitution.

In contrast, other clinically used procoagulatory drugs [e.g. prothrombin complex concentrates (PCC) or recombinant activated factor VII (rFVIIa)] that mainly increase thrombin generation are known to be associated with increased risk for thromboembolism. The administration of rFVIIa on an off-label basis, such as bleeding after cardiac surgery, has been reported to be associated with the increased risk of arterial thromboembolic events and to be associated with increased mortality. ${ }^{49}$ Similarly, the administration of PCC, which is regularly used offlabel in the perioperative setting, might be potentially deleterious, especially when given in high dosages. Despite a low event rate of only 1:31000 reported in a pharmacovigilance study, ${ }^{50}$ a recent meta-analysis found an overall incidence of thromboembolic events of $1.4 \%(95 \%$ CI $0.8-2.1)$ in patients receiving $\mathrm{PCC}$ for the reversal of vitamin $\mathrm{K}$ antagonists. ${ }^{51}$

The strengths of our study include a high number of patients treated with fibrinogen concentrate, $>99 \%$ completeness in follow-up, the blind event adjudication by two independent readers, and a close match between cases and controls. Further, the event incidence in the matched cohort essentially equalled that from the whole cohort, supporting its representativeness. Finally, the validity of our results is supported by a dual statistical approach (case-control analysis and multivariable logistic model) resulting in similar findings. Further, analysis in the PS-matched cohort and the whole cohort were comparable. On the other hand, we are aware of the following limitations of our study: first, the optimal design to assess a medical intervention and drug efficacy is a randomized controlled study. Our goal was not to assess the efficacy but the safety of fibrinogen concentrate, and randomized studies are rarely powered to address safety issues, given a low event rate of adverse events. However, although the present data do not suggest an increased risk of adverse events and mortality after fibrinogen administration at a median dose of $2 \mathrm{~g}$, we cannot exclude that higher dosages or more liberal fibrinogen infusion triggers would have resulted in an increased risk of major cardiac and thromboembolic events. Secondly, a small minority of patients were not treated according to a strict transfusion protocol and a strict definition of postoperative massive bleeding. Fibrinogen and allogeneic blood transfusion were transfused without previous testing because of unavailability of ROTEM ${ }^{\circledR}$ and long turn-around times of conventional coagulation testing because of severe bleeding. However, we do not think that this limitation relevantly influenced our findings because ROTEM ${ }^{\circledR}$ or conventional coagulation testing were performed in $\sim 95 \%$ of the patients, and because all the patients were treated similarly. Thirdly, bleeding volumes and transfusion of allogeneic blood products were significantly higher in the fibrinogen group. In agreement, the number of postoperative complications including surgical re-exploration or cardiac supportive therapy was significantly higher in the fibrinogen group. This might have resulted in the slightly higher rate of adverse events and deaths in the unadjusted analysis, whereas in the logistic regression model, the administration tended to be favourable as evidenced by an HR of $\sim 0.5-0.75$. Finally, the number of included patients may not have been sufficient to detect small differences between the two groups, given the low incidence rate. We refrained from including more than five variables into our multivariable analysis to avoid overfitting. ${ }^{27}$

To conclude, fibrinogen supplementation in bleeding patients has been recommended in the recent guidelines by the European Society of Anaesthesiologists, ${ }^{28}$ despite limited evidence regarding efficacy and safety of such a policy. ${ }^{12}{ }^{14}$ Our data suggest that fibrinogen substitution (median dose of $2 \mathrm{~g}$ ) aiming for plasma fibrinogen levels of $\sim 2 \mathrm{~g}$ litre ${ }^{-1}$ in bleeding patients undergoing cardiac surgery is not associated with increased mortality or thromboembolic and cardiac events after $1 \mathrm{yr}$. On the other hand, postoperative complications and major bleeding were important predictors of postoperative mortality and morbidity. Additional studies are required to further evaluate the clinical efficacy and low thromboembolic risk of fibrinogen concentrate.

\section{Authors' contributions}

J.F.: study design and conduction, data analysis, and preparation of the manuscript. G.L.B. and D.B.: study design and conduction, data collection and analysis, and preparation of the manuscript. M.F.: study design and conduction, and preparation of the manuscript. O.R.: study conduction and preparation of the manuscript. K.H.: study design and analysis, and preparation of the manuscript. M.D.S.: study design and conduction, data collection, and preparation of the manuscript.

\section{Acknowledgements}

The authors thank Esther Seeberger, RRN, Claudia Werner, RRN, Anne-Michelle Droux, RN, Dr Jorge Kasper, MD, Dr Tanja Schmidt, MD, and Dr Regina M. Schumann, MD, Department of Anaesthesia, Surgical Intensive Care, Prehospital Emergency Medicine and Pain Therapy, University Hospital Basel, Switzerland, for help with data acquisition, and Allison Dwileski, BS, Department of Anaesthesia, Surgical Intensive Care, Prehospital Emergency Medicine and Pain Therapy, University Hospital Basel, Switzerland, for editorial assistance. Further, we acknowledge the help of Dr D. Vogt, Clinical Trial Unit, University Hospital Basel, Switzerland, for statistical advice and support.

\section{Declaration of interest}

D.B. has received an unrestricted research grant from CSL Behring AG, Berne, Switzerland, and funding for lecture from Octapharma AG, Lachen, Switzerland. M.F. has received honoraria or travel support for lecturing from Novo Nordisk, Switzerland, Sanofi/Bristol-Myers Squibb, Switzerland, Essex Chemie, Switzerland, and Bayer HealthCare, Switzerland. K.H. has received honoraria for lecturing and scientific consulting from Sintetica SA, Switzerland. This study was planned and performed, data were collected and analysed and the manuscript was independently written by the authors only. 


\section{Funding}

This work was supported by grants from the Swiss National Science Foundation and the Foundation for Research and Education, Department of Anaesthesia, Surgical Intensive Care, Prehospital Emergency Medicine and Pain Therapy, University Hospital Basel, Switzerland.

\section{References}

1 Bolliger D, Gorlinger K, Tanaka KA. Pathophysiology and treatment of coagulopathy in massive hemorrhage and hemodilution. Anesthesiology 2010; 113: 1205-19

2 Karkouti K, Callum J, Crowther MA, et al. The relationship between fibrinogen levels after cardiopulmonary bypass and large volume red cell transfusion in cardiac surgery: an observational study. Anesth Analg 2013; 117: 14-22

3 Levy JH, Szlam F, Tanaka KA, Sniecienski RM. Fibrinogen and hemostasis: a primary hemostatic target for the management of acquired bleeding. Anesth Analg 2012; 114: 261-74

4 Collins PW, Solomon C, Sutor K, et al. Theoretical modelling of fibrinogen supplementation with therapeutic plasma, cryoprecipitate, or fibrinogen concentrate. $\mathrm{Br} J$ Anaesth 2014; 113: 585-95

5 Bolliger D, Gonsahn M, Levy JH, Williams WH, Tanaka KA. Is preoperative fibrinogen predictive for postoperative bleeding after coronary artery bypass grafting surgery? Transfusion 2009; 49: 2006-7

6 Karlsson M, Ternstrom L, Hyllner M, Baghaei F, Nilsson S, Jeppsson A. Plasma fibrinogen level, bleeding, and transfusion after on-pump coronary artery bypass grafting surgery: a prospective observational study. Transfusion 2008; 48: 2152-8

7 Yang L, Vuylsteke A, Gerrard C, Besser M, Baglin T. Postoperative fibrinogen level is associated with postoperative bleeding following cardiothoracic surgery and the effect of fibrinogen replacement therapy remains uncertain. $J$ Thromb Haemost 2013; 11: 1519-26

8 Blome M, Isgro F, Kiessling AH, et al. Relationship between factor XIII activity, fibrinogen, haemostasis screening tests and postoperative bleeding in cardiopulmonary bypass surgery. Thromb Haemost 2005; 93: 1101-7

9 Danes AF, Cuenca LG, Bueno SR, Mendarte Barrenechea L, Ronsano JB. Efficacy and tolerability of human fibrinogen concentrate administration to patients with acquired fibrinogen deficiency and active or in high-risk severe bleeding. Vox Sang 2008; 94: 221-6

10 Fenger-Eriksen C, Jensen TM, Kristensen BS, et al. Fibrinogen substitution improves whole blood clot firmness after dilution with hydroxyethyl starch in bleeding patients undergoing radical cystectomy: a randomized, placebo-controlled clinical trial. J Thromb Haemost 2009; 7: 795-802

11 Rahe-Meyer N, Hanke A, Schmidt DS, Hagl C, Pichlmaier M. Fibrinogen concentrate reduces intraoperative bleeding when used as first-line hemostatic therapy during major aortic replacement surgery: results from a randomized, placebo-controlled trial. J Thorac Cardiovasc Surg 2013; 145: S178-85

12 Rahe-Meyer N, Solomon C, Hanke A, et al. Effects of fibrinogen concentrate as first-line therapy during major aortic replacement surgery: a randomized, placebo-controlled trial. Anesthesiology 2013; 118: 40-50

13 Ranucci M, Solomon C. Supplementation of fibrinogen in acquired bleeding disorders: experience, evidence, guidelines, and licences. Br J Anaesth 2012; 109: 135-7
14 Dietrich W, Faraoni D, von Heymann C, et al. Comments on the ESA guidelines on the behalf of the Subcommittee on Transfusion and Haemostasis of the European Association of Cardiothoracic Anaesthesiologists (EACTA). Eur J Anaesthesiol 2014; 31: 239-41

15 Ozier Y, Hunt BJ. Against: fibrinogen concentrate for management of bleeding: against indiscriminate use. J Thromb Haemost 2011; 9: 6-8

16 Wikkelso A, Lunde J, Johansen M, et al. Fibrinogen concentrate in bleeding patients. Cochrane Database Syst Rev 2013; 8: CD008864

17 Kaptoge S, Di Angelantonio E, Pennells L, et al. C-reactive protein, fibrinogen, and cardiovascular disease prediction. $N$ Engl $J$ Med 2012; 367: 1310-20

18 Kaski JC, Fernandez-Berges DJ, Consuegra-Sanchez L, et al. A comparative study of biomarkers for risk prediction in acute coronary syndrome-results of the SIESTA (Systemic Inflammation Evaluation in non-ST-elevation Acute coronary syndrome) study. Atherosclerosis 2010; 212: 636-43

19 Hicks RC, Ellis M, Mir-Hasseine R, et al. The influence of fibrinogen concentration on the development of vein graft stenoses. Eur J Vasc Endovasc Surg 1995; 9: 415-20

20 Volzke H, Robinson DM, Kleine V, et al. Preoperative plasma fibrinogen levels predict mortality after coronary artery bypass grafting. Thromb Haemost 2003; 89: 885-91

21 Lurati Buse GA, Bolliger D, Seeberger E, et al. Troponin T and brain natriuretic peptide after on-pump cardiac surgery: prognostic impact on 12-month mortality and major cardiac events after adjustment for postoperative complications. Circulation 2014; 130: 948-57

22 Fassl J, Matt P, Eckstein F, et al. Transfusion of allogeneic blood products in proximal aortic surgery with hypothermic circulatory arrest: effect of thromboelastometry-guided transfusion management. J Cardiothorac Vasc Anesth 2013; 27: 1181-8

23 Tanaka K, Esper S, Bolliger D. Perioperative factor concentrate therapy. Br J Anaesth 2013; 111(Suppl. 1): i35-49

24 Nashef SA, Roques F, Michel P, Gauducheau E, Lemeshow S, Salamon R. European system for cardiac operative risk evaluation (EuroSCORE). Eur J Cardiothorac Surg 1999; 16: 9-13

25 Stuart EA. Matching methods for causal inference: a review and a look forward. Stat Sci 2010; 25: 1-21

26 Lurati Buse GA, Koller MT, Grapow M, et al. 12-Month outcome after cardiac surgery: prediction by troponin $\mathrm{T}$ in combination with the European system for cardiac operative risk evaluation. Ann Thorac Surg 2009; 88: 1806-12

27 Bagley SC, White H, Golomb BA. Logistic regression in the medical literature: standards for use and reporting, with particular attention to one medical domain. J Clin Epidemiol 2001; 54: 979-85

28 Kozek-Langenecker SA, Afshari A, Albaladejo P, et al. Management of severe perioperative bleeding: guidelines from the European Society of Anaesthesiology. Eur J Anaesthesiol 2013; 30: 270-382

29 Kozek-Langenecker S, Fries D, Spahn DR, Zacharowski K III. Fibrinogen concentrate: clinical reality and cautious Cochrane recommendation. Br J Anaesth 2014; 112: 784-7

30 Dickneite G, Pragst I, Joch C, Bergman GE. Animal model and clinical evidence indicating low thrombogenic potential of fibrinogen concentrate (Haemocomplettan P). Blood Coagul Fibrinolysis 2009; 20: 535-40

31 Danesh J, Lewington S, Thompson SG, et al. Plasma fibrinogen level and the risk of major cardiovascular diseases and nonvascular mortality: an individual participant meta-analysis. J Am Med Assoc 2005; 294: 1799-809 
32 Kannel WB, Wolf PA, Castelli WP, D'Agostino RB. Fibrinogen and risk of cardiovascular disease. The Framingham Study. J Am Med Assoc 1987; 258: 1183-6

33 Lowe GD, Rumley A. Fibrinogen and its degradation products as thrombotic risk factors. Ann N Y Acad Sci 2001; 936: 560-5

34 van Hylckama Vlieg A, Rosendaal FR. High levels of fibrinogen are associated with the risk of deep venous thrombosis mainly in the elderly. J Thromb Haemost 2003; 1: 2677-8

35 Ariens RA. Fibrin(ogen) and thrombotic disease. J Thromb Haemost 2013; 11(Suppl. 1): 294-305

36 Lane DA, Grant PJ. Role of hemostatic gene polymorphisms in venous and arterial thrombotic disease. Blood 2000; 95: 1517- 32

37 van der Bom JG, de Maat MP, Bots ML, et al. Elevated plasma fibrinogen: cause or consequence of cardiovascular disease? Arterioscler Thromb Vasc Biol 1998; 18: 621-5

38 Reinhart WH. Fibrinogen-marker or mediator of vascular disease? Vasc Med 2003; 8: 211-6

39 Collet JP, Allali Y, Lesty C, et al. Altered fibrin architecture is associated with hypofibrinolysis and premature coronary atherothrombosis. Arterioscler Thromb Vasc Biol 2006; 26: 2567-73

40 Undas A, Ariens RA. Fibrin clot structure and function: a role in the pathophysiology of arterial and venous thromboembolic diseases. Arterioscler Thromb Vasc Biol 2011; 31: e88-99

41 Bolliger D, Szlam F, Levy JH, Molinaro RJ, Tanaka KA. Haemodilutioninduced profibrinolytic state is mitigated by fresh-frozen plasma: implications for early haemostatic intervention in massive haemorrhage. Br J Anaesth 2010; 104: 318-25

42 Bolliger D, Szlam F, Molinaro RJ, Rahe-Meyer N, Levy JH, Tanaka KA. Finding the optimal concentration range for fibrinogen replacement after severe haemodilution: an in vitro model. $\mathrm{Br} J$ Anaesth 2009; 102: 793-9
43 Hiippala ST, Myllyla GJ, Vahtera EM. Hemostatic factors and replacement of major blood loss with plasma-poor red cell concentrates. Anesth Analg 1995; 81: 360-5

44 Bilecen S, Peelen LM, Kalkman CJ, Spanjersberg AJ, Moons KG, Nierich AP. Fibrinogen concentrate therapy in complex cardiac surgery. J Cardiothorac Vasc Anesth 2013; 27: 12 - 7

45 Kuo YR, Jeng SF, Wu WS, Lin CJ, Sacks JM, Yang KD. Hyperfibrinogenemia alone does not affect the patency of microvascular anastomosis: clinical experience and animal study. Ann Plast Surg 2005; 54: 435-41

46 Omarova F, Uitte De Willige S, Ariens RA, Rosing J, Bertina RM, Castoldi E. Inhibition of thrombin-mediated factor Vactivation contributes to the anticoagulant activity of fibrinogen gamma. J Thromb Haemost 2013; 11: 1669-78

47 Mosesson MW. Update on antithrombin I (fibrin). Thromb Haemost 2007; 98: 105-8

48 Rahe-Meyer N, Pichlmaier M, Haverich A, et al. Bleeding management with fibrinogen concentrate targeting a high-normal plasma fibrinogen level: a pilot study. $\mathrm{Br} J$ Anaesth 2009; 102: 785-92

49 Levi M, Levy JH, Andersen HF, Truloff D. Safety of recombinant activated factor VII in randomized clinical trials. NEngl JMed 2010; 363: 1791-800

50 Hanke AA, Joch C, Gorlinger K. Long-term safety and efficacy of a pasteurized nanofiltrated prothrombin complex concentrate (Beriplex P/N): a pharmacovigilance study. Br J Anaesth 2013; 110: 764-72

51 Dentali F, Marchesi C, Pierfranceschi MG, et al. Safety of prothrombin complex concentrates for rapid anticoagulation reversal of vitamin $\mathrm{K}$ antagonists. A meta-analysis. Thromb Haemost 2011; 106: $429-38$ 